\title{
CLUSTER DEVELOPMENT AND INNOVATIVE POTENTIAL IN SERBIAN AGRICULTURE
}

\author{
Vesna Paraušićl , Ivana Domazet ${ }^{2}$ \\ *Corresponding author_E-mail: vesna_pa@iep.bg.ac.rs
}

A R T I C L E I N F O
Review Article
Received: 10 July 2018
Accepted: 28 August 2018
doi:10.5937/ekoPolj1803159P
UDC 001.76+005.591.45]:631(497.11)

Keywords:

clusters, innovations, agriculture, correlation

JEL: Q01, Q13

\section{A B S T R A C T}

Science, technological development, innovation, competitive research for innovation, university-industry collaboration in R\&D, quality of scientific research institutions and state of cluster development today are key factors of competitiveness and sustainable development of all economies. In this paper authors analyse the correlation of the state of cluster development and innovation in national economies and give recommendations and ways of improving the innovative potential in Serbian economy, with emphasis on agriculture sector. Research hypothesis is set as: expressed positive linear correlation exists between cluster development and national innovation potential, meaning that the countries in which clusters are deep and well-developed are at the same time countries which have a high national innovation potential and vice-versa. The source of the data analysed in this paper is the Competitiveness report of the World Economic Forum 2017-2018. Linear correlation, including confidence intervals, was used in data analysis and research hypothesis is accepted by the data. Application of innovations in production value chain requires stimulating innovation policy of the state, great financial investments in the private sectors, as well as professional support of scientific-research and educational institutions, through the cluster initiatives.

(C) 2018 EA. All rights reserved.

\section{Introduction}

The world literature on clusters, as well as numerous documents of the European Commission, emphasize that specialized knowledge, innovations, technology and science are the key factors for growth and prosperity of the national economies, while the clusters represent a strong catalyst of innovation processes and engine/starting device of economic growth and investments.

1 Vesna Parausić, PhD, Scientific Associate, Institute of Agricultural Economics, Volgina Street No. 15, 11060 Belgrade, Serbia, phone: +381 116972 847, e-mail: vesna_pa@iep.bg.ac.rs

2 Ivana Domazet, $\mathrm{PhD}$, Senior Research Associate, Institute of Economic Sciences, Zmaj Jovina Street, No.12, 11000 Belgrade, Serbia, phone +381 11 2631-583, e-mail: ivana.domazet@ien.bg.ac.rs. 
Clusters represent extremely complex and sophisticated form of association of producers and suppliers (private sector), scientific and educational institutions and authorities. They provide to joined members sustainable sources of competitive advantages, based on high specialization, efficiency, productivity and innovation performances. The concept of cluster is expression of long time analysed phenomenon of geographic concentration/ agglomeration of economic activities and impact, which these concentrations have on economic growth. Professor Porter defined the cluster as geographic concentration of mutually correlated companies and institutions in some field of activity (one business branch) or, as the institution/enterprise's critical mass at one spot, of peculiar competitive success in specific activity fields (Porter, 1998, page 78).

Successful cluster has the following characteristics (Enright, 2003; Porter, 1998, 2008):

- Geographical proximity of the companies and institutions.

- Successful clusters are concentrated in one or more economic sectors within the region (cluster density), they have width (established horizontal connections with cluster participants) and depth (vertical connections of members in the cluster).

- Successful clusters are characterized by the existence of so called "social glue" (developed confidence, cooperation and partnership among the cluster members).

- Cooperation between the cluster members realizes through intensive cooperation, but also through competitive relation.

The key positive contributions of cluster on cluster members especially in sector of small and medium enterprises are (A Practical Guide to Cluster Development, 2003; Porter, 1998; Porter, 1998, 2008):

- Reducing production costs and increase of productivity.

- Increase of innovation performance. There is expressed causal relationship between the clusters and the capacity of innovations (cluster members, regions, national economy). The clusters have an effect to innovation potential of engaged members, regions and the national economy, but at the same time, high innovation performance of members and stimulating role of the state in motivation of innovation, research and development leads to development of innovation clusters, which, based on knowledge and innovations, build and keep their competitive advantage on the market.

- Increase of competitiveness of members and regions in which the cluster function;

- Stimulating development of entrepreneurship and business environment (specialized labour, developed physical, financial, business infrastructure, etc.).

- Attraction of foreign direct investments and growth of export.

The contribution of developed clusters and social capital to national competitiveness and innovation capability is especially significant for transitional and developing countries, which have repeatedly a lack of resources, knowledge and sophistication (Ketels, Solvell 2005; World Bank, 2009; Paraušić, et. al, 2014; The Impact of Socio-Economic Structure of Rural Population on Success of Rural Development Policy, 2015). 
Sustaining economic growth and job creation in the Western Balkans will require a substantive shift toward a more productivity-based, export-oriented growth model. Macroeconomic stability and a market orientation remain important conditions for the development of such a model, but a strategy to unleash the region's innovative potential will be critical, given the magnitude and complexity of the required adjustments in the region's productivity structure (Western Balkans Regional R\&D Strategy for Innovation, 2013). Western Balkan countries are often receiving innovative practices and models through foreign direct investment. The precondition for the arrival of foreign investors in a domicile country is to create an attractive and predictable business environment for the flow of foreign capital, with simple and understandable administrative procedures. Developing countries, in which the foreign companies invest, make significant benefits, primarily through the reduction of high unemployment, the improvement of the techniques and technologies of production and management processes, and the increase in exports of the domicile country (Domazet, 2018).

The analysis of the scientific and innovation system of Serbia points to the following characteristics, weaknesses and constraints (Strategy of Scientific and Technological Development of the Republic of Serbia for the period 2016-2020):

$\checkmark \quad$ Low level of total (below 1\% of GDP) and budget investments (below $0.5 \%$ of GDP) in R\&D;

$\checkmark \quad$ Research in Serbia is high-quality and covers wide scientific areas, but does not have proper application in practice;

$\checkmark \quad$ Research is concentrated at universities and institutes and there are no mechanisms, financial instruments and institutional framework to support research and innovation in private sector and cooperation between private sector and science (there are no tax exemptions for companies that implement R\&D activities, there is no credit support for innovative enterprise projects, establishment of "spin-off "enterprises by researchers employed in scientific-research organizations is not regulated by applicable laws, financing innovation projects through venture capital funds is not regulated);

$\checkmark \quad$ Investments of business sector in R\&D are very low, especially in comparison with the EU countries. The share of the business sector in research funding in the Republic of Serbia amounts to only 7.5\%, and in the OECD countries, the business sector finances $60.8 \%$ of all R\&D costs;

$\checkmark \quad$ A small number of researchers and scientists engaged in the business sector. Out of the total number of researchers engaged in Serbia in 2013, only 3.3\% were engaged in the business sector, while in the OECD countries this percentage was 59.9\% and in the EU 37\%;

$\checkmark \quad$ Lack of infrastructure support for innovation in spite of new institutions in Belgrade, Novi Sad, Niš and Kragujevac (eight business-technical incubators, four science and technology parks, and four technology transfer centers). A large number of business-technology incubators have been established to support spin-off and start-up companies, but they are often donor initiatives for which no long-term and sustainable funding is provided; 
$\checkmark \quad$ Low number of patents and technical solutions;

$\checkmark \quad$ Departure of highly educated people from the state.

In all sectors of the economy Serbia have to promote research-industry collaboration, technology transfer and research for commercial purposes and these can be achieved by (Western Balkans Regional R\&D Strategy for Innovation, 2013; Strategy of Scientific and Technological Development of the Republic of Serbia for the period 2016-2020; B. Siemen Van, N. Bogdanov, 2012):

$\checkmark$ Improving the incentive regime for collaboration between research institutes, universities, and the private sector: vouchers and matching grants, the establishment of long-term consortia between the public sector (research providers) and the private sector (research users). Incentives that prove effective in other EU countries should be applied in the Republic of Serbia, which will strengthen the role of the economy in research and development through: tax reliefs, customs reliefs, specific exemptions from payments (VAT and tax exemption on the part invested in science), specific credit lines of financing the development of new products and services, etc.

$\checkmark$ Simplification of legal requirements governing the interaction between public research organizations and the enterprise sector (Legislation regulating the management of intellectual property).

$\checkmark$ Investment in innovation and business infrastructure (science and technology parks and business incubators; clusters; laboratories, equipment of scientificresearch institutes, quality centres etc.).

Agriculture is an important part of the Serbian economy from the point of GDP share and employment. According to the Agricultural Census 2012, there are 631.552 rural households in Serbia and utilized agricultural area (UAA) amounts to 3.44 million hectares. The agriculture sector is dominated by family farms, which constitute $99.5 \%$ of the total number of agricultural holdings and they use $82.2 \%$ of UAA.

However, the limitations for development of this sector are numerous (B. Siemen Van, N. Bogdanov 2012; Bogdanov 2015; FAO, 2014):

$\checkmark \quad$ The prevalence of small - scale farms is the key obstacle for more dynamic growth of Serbian agriculture.

$\checkmark \quad$ Low productivity is mostly due to a serious lack of organization within the sector;

$\checkmark \quad$ Volatile agricultural policy and insufficient funding opportunities;

$\checkmark \quad$ Lack of modern technology and technical assistance. Also, the real needs and priorities of the agro-food sector and the impact of technological development is too rarely a decisive factor in project formulation or the formation of research teams in Serbia.

$\checkmark \quad$ Recognition of agricultural knowledge and innovation system role on all levels, and fitting it to the real needs is very important, but analytical support 
is not developed yet and there are no clear signals for the improvement. No support is provided for applied research in spite of real demand (this lack is only partly compensated by donor support).

One of the priority areas of strategic change in the Strategy of agriculture and Rural Development of the Republic of Serbia (2014-2024) is "Technological development and modernization of agricultural production and processing" (The Strategy of Agriculture and Rural Development of the Republic of Serbia for the period 2014-2024).

In Serbia and other transitional and developing countries as the most important contribution of cluster in sector of agricultural points out a possibility to move a focus of agricultural producers' competitiveness from low prices and labour/natural resources' exploitation to the competition which leans on knowledge, innovations and bio-technical, marketing and other scientific researches (World Bank, 2012).

Still, clusters as innovation catalysts, in Serbian economy and agricultural sector are not sufficiently developed. They are established with the primary objective to apply for public funds for cluster support and they are missing the least common denominator in terms of defining the future interest that gathers cluster members (Mijačić, 2011). In business practice, companies in clusters are inactive, there are no executed cluster projects, clusters are weak in terms of production, human and financial resources, participation of cluster members (particularly scientific research institutions) is at a low level, without established trust or cooperation among them (Paraušić, Simeunović, 2016; Paraušić, et al., 2017). The Institute for Territorial Economic Development (InTER) conducted an analysis of the results of the programme of support for cluster development in Serbia for the period 2007-2015 (Žarković et al. 2016). The results indicated that the programme helped to promote the idea of association in clusters among SMEs and also the successful development of several clusters, especially in the sector of information and communication technologies. However, there is still not enough understanding of the cluster concept and benefits of that type of association of SMEs. The programme was not able to contribute to a higher level of the productivity, competitiveness and innovation of the clusters and SMEs in clusters and also there is still no impact on increasing the membership in the clusters and the strengthening of relations between cluster members (Ibidem).

In addition to underdeveloped clusters, companies in the agro food sector in Serbia are inclined to open innovation, not just those in high - tech industries that are often the subject of innovation literature. Still, the food sector shows greater proclivity for open innovation in comparison with agriculture in all elements apart from the question of willingness to sell intellectual property (Zakić et al., 2017).

ANTARES project in Serbian agriculture sector (2016-2020), implemented by the BioSense Institute of the University of Novi Sad, has been ranked best within one of the most prestigious calls of the European Commission - Horizon 2020 Teaming. The partners of the BioSense are the Ministry of Education, Science and Technological development and Wageningen Research Institute from Netherlands, the world's leading 
institution in the field of modern agriculture. Considering that sector of information and communication technology (ICT) has the potential to extremely improve the competitiveness of Serbian economy (Domazet, Lazić, 2017), the ANTARES project, combines two of the most promising sectors in Serbia: IT (information technology) and agriculture. ANTARES aims to turn the BioSense Institute into a European Centre of Excellence for advanced technologies in sustainable agriculture and food security (https://europa.rs/serbian-agriculture-project-ranked-best-in-europe/?lang=en).

\section{Materials and methods}

Applied methodological method was desk research, i.e. review and analysis of the secondary data on clusters, national competitiveness and innovation.

For the need of the statistical research and hypothesis testing authors used the World Economic Forum's Competitiveness Report 2017-2018 as data source. The World Economic Forum (abbreviation WEF) is an independent international organization, which publish annually the report „Global Competitiveness Report“", in which assesses and ranks countries all over the world according to their national competitiveness (expressed through Global Competitiveness Index/GCI) and numerous variables that are included in calculation of GCI. The most of variables which take into account of the GCI get by the survey (Executive Opinion Survey) with managers of randomly selected companies in each country, while offered answers are on the scale from 1 to 7 (subjective assessments of surveyed enterprises' managers in the countries comprised by the research). The authors used the following two WEF's variables, which take into account of the GCI and take values on a 1 to 7 scale (WEF, 2017):

- State of clusters development. This variable enters into the calculation of GCI and 11th pillar of competitiveness (Business sophistication). The data are provided on the basis of personal assessment of managers in surveyed companies about cluster development in their country. A question that is asked to the surveyed businessmen is the following: ,What is the level of clusters' development and depth in your country? ". The assessment 1 means that there are no clusters in the country, while the assessment 7 points out to high developed and deep clusters in many fields. In accordance to the surveyed businessmen' answers gets an average assessment of clusters development, as well as the ranks of countries in regard to clusters' development.

- 12th pillar of GCI: Innovation. That pillar includes the following variables of competitiveness: Capacity for innovation; Quality of scientific research institutions; Company spending on R\&D; University-industry collaboration in R\&D; Gov't procurement of advanced technology products; Availability of scientists and engineers.

Statistical technique of simple linear correlation (Pearson's coefficient) is used for exploring the nature and strength of correlation between state of cluster development and national innovation on a sample of 137 countries worldwide (1). 


$$
r=\frac{n \sum x-\sum x \sum y}{\sqrt{n \sum x^{2}-\left(\sum x\right)^{2}} \sqrt{n \sum y^{2}-\left(\sum y\right)^{2}}}
$$

where $n$ is sample size, and $x, y$ - analyzed variables.

The basic assumptions for applying the method of simple linear correlation were fulfilled:

- Relationship between variables is linear (as seen on scatter plot).

- Observed variables have normal distribution.

The sample of 137 countries worldwide is big and representative, as countries in the sample together produce around $99 \%$ of world gross domestic product and in the world accounting for $95 \%$ of the world's population (WEF 2018).

Working hypothesis is: There is expressed positive linear correlation between state of cluster development and national innovation. Formally written, null vs. alternative (research) hypothesis is: $H_{0}: \rho=0.7$ vs. $H_{1}: \rho>0.7$.

Following test statistic is used for testing the null hypothesis $(2,3)$ :

$$
\begin{aligned}
& Z Z=\left(Z_{r}-Z_{0.7}\right) \sqrt{n-3}: N(0,1) \\
& \text { Where } \quad Z_{r}=\frac{1}{2} \ln \frac{1+r}{1-r}
\end{aligned}
$$

Test statistic Z has, under null hypothesis, standard normal distribution (4):

$$
N\left(\frac{1}{2} \ln \frac{1+\rho}{1-\rho}, \frac{1}{n-3}\right)
$$

95\% confidence interval for the Pearson's correlation coefficient is determined according to the formula $(5,6)$ :

$$
I_{\rho}=\left(\frac{e^{2 Z_{1}}-1}{e^{2 Z_{1}}+1}, \frac{e^{2 Z_{2}}-1}{e^{2 Z_{2}}+1}\right)
$$

Where

$$
Z_{1}=Z_{r}-\frac{1.96}{\sqrt{n-3}} Z_{2}=Z_{r}+\frac{1.96}{\sqrt{n-3}}
$$

Data were analyzed using the statistical software R.

$\mathrm{P}$-values $<0.05$ were considered significant. 


\section{Results}

Authors prove a working hypothesis that there is expressed direct correlation among state of clusters development and national innovation potential.

Table 1. Results of hypothesis testing on correlation between cluster development and national economies' innovation potential

- Sample of 137 countries -

\begin{tabular}{|l|r|r|r|r|}
\hline \multicolumn{1}{|c|}{ Variable } & \multicolumn{1}{|c|}{$\begin{array}{c}\text { Pearson's } \\
\text { coefficient (r) }\end{array}$} & $\begin{array}{c}\boldsymbol{\beta} \% \text { confidence } \\
\text { interval }\end{array}$ & $\begin{array}{c}\text { Realized value of } \mathbf{z} \\
\text { test statistics }\end{array}$ & p test value \\
\hline $\begin{array}{l}\text { State of cluster } \\
\text { development/ } \\
\text { Innovation }\end{array}$ & 0.853 & $0.800-0.893$ & & 0.641 \\
\hline
\end{tabular}

Source: World Economic Forum (2017) \& authors' calculations.

The application of Pearson's coefficient points out the following results (Table 1, Figure 1):

$\checkmark$ Coefficient of simple linear correlation $(\mathrm{r}=0.853)$ indicates that there is a strong positive correlation between analysed variables.

$\checkmark$ With certainty of $95 \%$ can assume that this coefficient will range in interval from 0,800 to 0,893 for all countries in the world,

$\checkmark$ Regarding to the $p$ value of the test, authors accepts the alternative hypothesis that in the basic set there is expressed the direct correlation between the cluster and the innovation potential of the national economies: $H_{1}: \rho>0.7$ opposite to $H_{0}: \rho=0.7$.

Figure 1. Linear correlation between state of clusters development and innovation, $n=137$

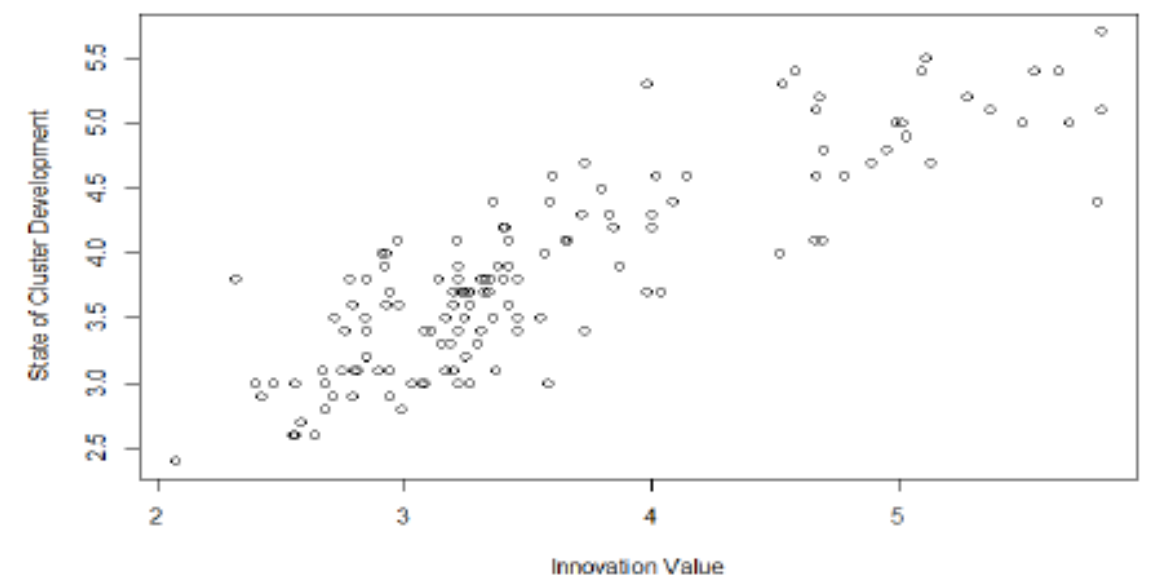

Source: Authors' calculations. 


\section{Discussions}

Authors were proven the hypothesis that there is the causal-consequential relation and expressed direct correlation between the state of clusters development and the national economy's innovation potential: there was accepted $H_{1}: \rho>0.7$, opposite to $H_{0}: \rho=0.7$. This hypothesis was proven using WEF's data which represent the national innovation potential and state of cluster development in the sample of 137 world economies and using Pearson's coefficient of correlation.

Between developed clusters and innovation there is a pronounced correlation in all sectors of the economy, even in the agricultural sector. Innovations are developing better through the clusters, science and technology parks, spin-off companies, and overall innovation infrastructure (laboratories and quality centers, scientific research institutes, business incubators). On the other hand, innovative companies, farmers, suppliers, as well as innovative scientific research organizations, encourage the integration of actors into clusters. Therefore, it can be conclusion that national competitiveness in emerging market and developing economies can be significantly improved by developing clusters and encouraging innovation and productivity within the framework of cluster directed economy.

\section{Conclusions}

Innovation and emerging technologies have immense potential to be a source of growth, but their future evolution is uncertain. A key challenge is how to unlock their potential in a way that benefits society as a whole given that they can profoundly reshape the national and global distributions of income and opportunities and lead to significant structural transformations. Job losses are expected as technology transforms manufacturing and services in the coming years, raising questions about how quickly new jobs will be created and about the future of economic development models based on exporting labor-intensive manufacturing products. At the same time, technological advances are creating significant value for consumers, more than is currently reflected in national statistics (WEF, 2017).

Technological improvement, investments in new knowledge and technologies and their transfer to direct users, with cluster development are prerequisites for reducing the technological lag in Serbian agriculture, productivity growth and adaptation to climate change.

The most important is certainly strong and extensive cooperation between universities and scientific institutes and economic entities in research-developmental activities. This cooperation is directly connected to knowledge application in practice, it leads to adjustment of basic, applied and experimental researches, to appropriate expenditure of budgetary resources meant for innovations, as well as to „removal“ of scientific researchers from universities and state scientific institutes toward enterprises, clusters and scientific parks. Very important element in this cooperation is a height of funds appropriation (as GDP percentage) for R\&D which derives from the economy sector. In the EU documents emphasizes as a goal the increase of funds appropriations for R\&D to $3 \%$ GDP, along with $2 / 3$ of investments which would derive from the private sector (Europe 2020). 
Further progress of the research and innovation system, and therefore the economic and overall development of the Republic of Serbia are not possible without increased material investments in science and research. The EU's Horizon 2020 program predicts that by the end of 2020, total investment in research and innovation should amount to $3 \%$ of GDP, of which $1 \%$ is from public sources or $1 \%$ of the budget. If the Republic of Serbia wants to become part of the European Research Area until 2020, it certainly needs to gradually increase its investment in research, development, science and innovation in order to achieve the goal set by the EU's Horizon 2020 Program. The projection is that by 2020 , these budget investments will be $0.6 \%$ of GDP, and total investments from all sources of financing will reach 1.5\% of GDP, with future investments certainly dependent on economic growth and on available funds in the budget of the Republic of Serbia (Strategy of Scientific and Technological Development of the Republic of Serbia for the period 2016-2020).

\section{Acknowledgements}

This paper is a part of research projects numbers III 46006 and III 47009 financed by the Ministry of Education, Science and Technological Development of the Republic of Serbia (2011-2018).

\section{Conflict of interests}

The authors declare no conflict of interest.

\section{References}

1. Berkum, S., Bogdanov, N. (2012): Serbia on the Road to EU Accession: Consequences for Agricultural Policy and the Agri-food Chain, CABI, Oxfordshire, UK, available https://books.google.rs/books?id=Y44rHmdXFmIC\&pg=PA54\&lpg=PA54\&dq=innovation + in + serbian+agriculture \&source $=$ bl\&ots $=$ ZsKkysSKRj\&sig $=$ vR1Q3hV oKgJz0hi20 07imQ1Ik\&hl=s-

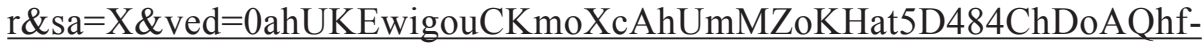
MAk\#v=onepage \&q=innovation $\% 20 \mathrm{in} \% 20$ serbian $\% 20$ agriculture $\& \mathrm{f}=$ false

2. Bogdanov, N. (2015). Serbia: Agricultural Policy Brief (CAPB), http://app. seerural.org/wp-content/uploads/2016/11/2015-10_Country-policy-brief-Serbia-Final.compressed.pdf.

3. Domazet, I., \& Lazić, M. (2017). Information and Communication Technologies as a Driver of the Digital Economy. 22th International Scientific Conference Strategic Management and Decision Support Systems in Strategic Management, May 19, 2017, Subotica, Republic of Serbia.

4. Domazet, I. (2018). "Improving Competitiveness and Economic Development through FDI", in Thematic proceeding "Developmental State and Millennium Development Goals" Calcutta, India, 5-8. June 2018, The International Institute of Development Studies (IIDS) Brisbane, Australia. 
5. Enright, M. (2003). Regional Clusters: „,What We Know and What We Should Know“, in „Innovation Clusters and Interregional Competition“, Springer-Verlag Berlin Heidelberg.

6. Europe 2020, a strategy for jobs and smart, sustainable and inclusive growth, EC, 2010.

7. FAO (2014). Agricultural Policy and European Integration in Southeastern Europe, Edited by Volk, T., Erjavec, E., Mortensen, K. Budapest.

8. Ketels, C., \& Solvell, Ö. (2005). Clusters in the EU-10 new member countries, Europe INNOVA, Cluster Mapping.

9. Mijačić, D. (2011). State analysis of business infrastructure in the Republic of Serbia. Belgrade: National Agency for Regional Development.

10. Parausic, V., Cvijanovic, D., Mihailovic, B., \& Veljkovic, K. (2014). Correlation between the state of cluster development and national competitiveness in the Global Competitiveness Report of the World Economic Forum 2012-2013. Economic Research, Vol. 27, No 1, 2014.

11. Paraušić, V., \& Simeunović, I. (2016). Market Analysis of Serbia’s Raspberry Sector and Cluster Development Initiatives. Economics of Agriculture, No. 4, 2016

12. Paraušić, V., Domazet, I., \& Simeunović, I. (2017), Analysis of the Relationship Between the Stage of Economic Development and the State of Cluster Development, Argumenta Oeconomica, Vol. 39, No 2(2017).

13. Porter, E. M. (1998). Clusters and the New Economics of Competition. Harvard Business Review, November, 1998.

14. Porter, E. M. (2008). On competition. Harvard Business Review Book.

15. Practical Guide to Cluster Development, Englands Regional Development Agencies, 2003.

16. Strategy of Scientific and Technological Development of the Republic of Serbia for the period 2016-2020, Official Gazette of RS, No. 25/2016.

17. Strategy of Agriculture and Rural Development of the Republic of Serbia (2014-2024), The Ministry of Agriculture, Forestry and Water Management of the Republic of Serbia, Official Gazette of RS, No. 85/2014.

18. The Impact of Socio-Economic Structure of Rural Population on Success of Rural Development Policy. Macedonia, Serbia and Bosnia and Herzegovina (2015). Association of Agricultural Economists of Republic of Macedonia Skopje, 2015.

19. Western Balkans Regional R\&D Strategy for Innovation, October 2013, Regional Cooperation Council, European Commission, DG ENLARG TF011064. 
20. World Bank (2009). Clusters for Competitiveness: A Practical Guide and Policy Implications for Developing Cluster Initiatives. International Trade Department, 2009.

21. World Bank (2012). Agricultural Innovation Systems An Investment Sourcebook. The World Bank, Washington, 2012.

22. World Economic Forum (2017). The Global Competitiveness Report 20172018. World Economic Forum Geneva.

23. Zakić, N., Bugarčić, M., \& Milovanović, M. (2017). Proclivity for Open Innovation in the Case of Agricultural and Food Companies in Serbia. International Review, No.3

24. Žarkovic, J., Mijacic, D., \& Sovrlic, T. (2016), Clusters ten years later: Analysis of the effects of the Cluster Development Support Program in Serbia 20072015, Institute for Territorial Economic Development (InTER), Belgrade.

25. Statistical Office of the Republic of Serbia - SORS (2012). Census of Agriculture 2012 in the Republic of Serbia, internal data, http://data.stat.gov.rs/?call$\underline{\mathrm{er}=\mathrm{SDDB}}$ (May 17, 2018).

26. Serbian agriculture project ranked best in Europe, on 10/04/2017, https://europa. rs/serbian-agriculture-project-ranked-best-in-europe/?lang=en (June 15, 2018). 